\title{
HUBUNGAN ANTARA TINGKAT PENGETAHUAN BODY MASS INDEX (BMI) DENGAN UPAYA MENJAGA BERAT BADAN IDEAL PADA REMAJA DI SMK BINA INSAN CENDEKIA TANGERANG (BICTA)
}

\author{
Diah Arintha Mustika Putri ${ }^{1 *}$, H.A.Y.G Wibisono ${ }^{2}$, Febi Ratna Sari ${ }^{3}$ \\ 1,2,3 STIKes Yatsi Tangerang
}

Email: diaharinthaputri@gmail.com

\begin{abstract}
RELATIONSHIP BETWEEN THE BODY MASS INDEX (BMI) KNOWLEDGE LEVEL AND THE EFFORT TO MAINTAIN THE IDEAL BODY WEIGHT IN YOUTH AT SMK BINA INSAN CENDEKIA TANGERANG (BICTA) IN 2020
\end{abstract}

Background: The data of Riskesdas in the year of 2018 indicated that there was $8,7 \%$ of the youth aged $13-15$ years old, and $8,1 \%$ of the youth aged $16-18$ years old are thin and very thin. Therefore, 16,0\% of the youth aged 13-15 years old have an excessive prevalence of body weight and obesity (Kemenkes, 2020).

Purpose: To find out the relationship between the knowledge of Body Mass Index (BMI) with the effort to maintain the ideal body weight of the youth.

Method: This research conducted using a descriptive correlation design, then the sampling technique was the proportionate stratified random sampling. The research samples were 104 respondents using the analysis of univariate and bivariate, and Wilcoxon test.

Results: Based on the Chi-Square test (P-value 0,002 < 0,05). Wilcoxon test obtained in $(0,000<0,05)$. There is a meaningful relationship between the variable of knowledge-level and the effort to maintain the ideal body weight.

Conclusion and Suggestion: Most of the respondents have a good level of knowledge of the BNI and provide an effort to maintain body weight. Providing the information aims to build better knowledge, so the effort of maintaining body weight can be done appropriately.

Keywords: $\quad K n o w l e d g e$, Body Mass Index (BMI), The effort, Youth.

INTISARI : HUBUNGAN ANTARA TINGKAT PENGETAHUAN BODY MASS INDEX (BMI) DENGAN UPAYA MENJAGA BERAT BADAN IDEAL PADA REMAJA DI SMK BINA INSAN CENDEKIA TANGERANG (BICTA) TAHUN 2020

Latar Belakang: Data Riskesdas tahun 2018 menunjukkan bahwa terdapat 8,7\% remaja berusia 13 sampai 15 tahun dan $8,1 \%$ remaja berusia 16 sampai 18 tahun memiliki kondisi kurus dan sangat kurus. Sedangkan 16,0\% pada remaja yang berusia 13 sampai 15 tahun memiliki prevalensi berat badan berlebih dan obesitas (Kemenkes 2020).

Tujuan: Untuk mengetahui hubungan antara tingkat pengetahuan Body Mass Index (BMI) dengan upaya menjaga berat badan ideal pada remaja.

Metode: Penelitian ini menggunakan desain deskriptif korelasi, teknik pengambilan sampel menggunakan proposionate startified random sampling. Sampel pada penelitian ini sebanyak 104 responden. Analisis dari hasil uji statistik menggunakan Chi square dan korelasi.

Hasil: Berdasarkan uji Chi square $(P$ value $0,002<0,05)$. Uji Wilcoxon didapatkan $(0,000<0,05)$. Terdapat hubungan bermakna antara variabel tingkat pengetahuan dengan upaya menjaga berat badan ideal. 
Kesimpulan dan Saran: Sebagian besar responden memiliki tingkat pengetahuan yang baik mengenai BMI dan melakukan upaya. Pemberian informasi ditujukan untuk membentuk pengetahuan yang lebih baik, sehingga upaya menjaga berat badan dapat dilakukan dengan tepat.

Kata kunci: Pengetahuan, Body Mass Index (BMI), Upaya, Remaja

\section{PENDAHULUAN}

Di Indonesia, jumlah remaja dan kaum muda berkembang sangat cepat. Hasil Riskesdas Provinsi Banten tahun 2019 jumlah penduduk remaja usia 15-19 tahun jenis kelamin laki-laki berjumlah 522,618 jiwa sedangkan untuk jenis kelamin perempuan berjumlah 489,320 jiwa (Profil Banten, 2019).

Di indonesia masih memiliki beban msalah gizi yaitu seperti stunting, kekurangan gizi mikro yaitu seperti anemia, wastring dan juga obestas. Data Riskesdas tahun 2018 menunjukkan bahwa $25,7 \%$ remaja yang memiliki usia 13 sampai 15 tahun dan $26,9 \%$ remaja yang berusia 16 sampai 18 tahun memiliki gizi pendek bahkan sangat pendek. Selain itu terdapat 8,7\% remaja berusia 13 sampai 15 tahun dan $8,1 \%$ remaja berusia 16 sampai 18 tahun memiliki kondisi kurus dan sangat kurus. Sedangkan 16,0\% pada remaja yang berusia 13 sampai 15 tahun memiliki prevalensi berat badan berlebih dan obesitas (Kemenkes 2020).

Hasil penelitian yang dilakukan oleh Indah dkk (2014) di kecamatan Rajeg Tangerang diketahui bahwa berdasarkan hasil pengukuran (IMT/U) sebanyak 11,3\% anak tergolong sangat kurus dan kurus sebesar 6,5\%. Body Mass Index (BMI) merupakan perbandingan antara tinggi dan berat badan seseorang yang biasa digunakan untuk menilai proporsionalitas tubuh seseorang. BMI digunakan untuk menentukan masalah atau resiko yang berkaitan dengan berat badan seseorang yaitu seperti underweight (kekurangan berat badan), overweight (kegemukan) dan juga kelebihan berat badan atau disebut dengan obesitas (Syukra Almada, 2015).

Peningkatan prevalensi obesitas masih sering terjadi dikarenakan perubahan terhadap pola makan disetiap individunya dan juga kurangnya aktivitas fisik. Kunci utama dari keseimbangan energi seseorang adalah aktivitas fisik karena dapat menyumbang pengeluaran berbagai energi. Gaya hidup yang serba santai dan mudah yang membuat tubuh menjadi jarang sekali untuk bergerak atau hanya sedikit saja untuk mengeluarkan tenaga untuk melakukan aktivitas sehari-hari yang biasa disebut dengan MAGER alias males gerak. Makanan yang dikonsumsi, sebagian besarnya seharusnya dibakar dengan cara rajin berolahraga agar tidak terjadi penumpukan lemak. Tentu saja itu semua akan menjadi penambahan pundi-pundi lemak dibawah kulit jika terus saja terjadi (Dewi, 2011).

Berdasarkan hasil studi pendahuluan yang dilakukan oleh peneliti di SMK Bina Insan Cendekia Tangerang (BICTA) kelas XII Keperawatan pada tanggal 16 Januari 2020 didapatkan hasil dari wawancara acak 10 orang remaja kebanyakan dari mereka tidak membiasakan diri untuk mengatur pola makan, berolahraga serta upaya-upaya lainnya dalam menjaga berat badan mereka agar tetap ideal. 
Berdasarkan permasalahan diatas, peneliti tertarik untuk melakukan penelitian yang berjudul "Hubungan Antara Tingkat Pengetahuan Body Mass Index (BMI) Dengan Upaya Menjaga Berat Badan Ideal Pada Remaja Di SMK Bina Insan Cendekia Tangerang (BICTA)."

\section{METODE}

Jenis penelitian yang digunakan dalam penelitian ini adalah jenis penelitian kuantitatif dengan desain deskriptif korelasi. Pengumpulan data dilakukan dengan cross-sectional atau pengumpulan data sekaligus pada suatu saat. Populasi dalam penelitian ini adalah siswa/i kelas XII jurusan Keperawatan dan Farmasi di SMK Bina Insan Cendekia Tangerang. Sedangkan teknik sampel yang digunakan adalah Random Sampling yaitu dengan mengambil secara acak tanpa memperhatikan strata yang ada pada populasi. Sampel pada penelitian ini sebanyak 104 responden. Pada penelitian ini variabel independen adalah tingkat pengetahuan Body Mass Index (BMI) sedangkan variabel dependen adalah upaya menjaga berat badan ideal.

Penelitian ini sudah dilakukan uji etik dengan Nomor: 115/LPPM-STIKES YATSI/VII/2020 dan dinyatakan lolos uji etik pada tanggal 24 Juli 2020. Penelitian ini dilaksanakan pada tanggal 28 Juli 2020 di SMK Bina Insan Cendekia Tangerang. Jenis instrumen yang digunakan dalam penelitian ini adalah kuesioner yang dibuat oleh peneliti sendiri. Kuesioner dalam penelitian ini digunakan untuk mengukur variabel tingkat pengetahuan dan upaya menjaga berat badan ideal. Uji instrumen meliputi uji validitas dan uji reabilitas.

Kuesioner ini terdiri dari 2 bagian dimana bagian pertama menjabarkan tentang tingkat pengetahuan dimana terdapat 9 pertanyaan dengan menggunakan skala guttman jika menjawab "Benar" mendapatkan nilai 1 jika menjawab "Salah" mendapatkan nilai 0. Bagian dua menjabarkan upaya atau sikap responden terdapat 8 pertanyaan yang dibagi 7 pertanyaan positif (adaptif) dan 1 pertanyaan negatif (maladaptif) menggunakan skala likert. Untuk pertanyaan positif dengan nilai $1=$ "Tidak Setuju", 2 = "Kurang Setuju", 3 = "Setuju", 4 = "Sangat Setuju" dan pertanyaan negatif dengan nilai 1 = "Sangat Setuju", 2 = "Setuju", 3 = "Kurang Setuju", 4 = "Tidak Setuju". Data yang diperoleh akan dianalisa menggunakan analisis univariat dan analisis bivariat. Analisis bivariat yang digunakan pada penelitian ini menggunakan uji statistik dengan Chi Square dan korelasi menggunakan SPSS versi 22.0. Uji ini dilakukan untuk mengindentifikasi hubungan variabel independen dengan variabel dependen. Apabila diperoleh hasil $P$ value < 0,05 maka terdapat hubungan antara tingkat pengetahuan Body Mass Index (BMI) dengan upaya menjaga berat badan ideal sehingga dapat disimpulkan bahwa $\mathrm{H}_{\mathrm{a}}$ diterima jika $P$ value $<0,05$ dan $\mathrm{H}_{\mathrm{o}}$ ditolak jika $P$ value $>0,05$. 
HASIL

\section{Analisa Univariat}

Tabel 1.

Distribusi Frekuensi Tingkat Pengetahuan Responden di SMK Bina Insan Cendekia Tangerang Tahun $2020(\mathrm{n}=104)$

\begin{tabular}{ccc}
\hline $\begin{array}{c}\text { Variabel } \\
\text { Tingkat } \\
\text { Pengetahuan }\end{array}$ & Jumlah & Presentase \\
\hline Baik & 99 & 95,2 \\
Kurang & 5 & 4,8 \\
\hline Total & 104 & 100,0
\end{tabular}

Berdasarkan tabel $1 . \quad$ baik sebanyak 99 responden $(95,2 \%)$ didapatkan hasil dari 104 responden dan yang berpengetahuan kurang bahwa responden berpengetahuan sebanyak 5 responden $(4,8 \%)$.

Tabel 2.

Distribusi Frekuensi Upaya Menjaga Berat Badan Responden di SMK Bina Insan

\begin{tabular}{|c|c|c|}
\hline $\begin{array}{c}\text { Variabel } \\
\text { Uapaya } \\
\text { Menjaga Berat } \\
\text { Badan }\end{array}$ & Jumlah & Presentase \\
\hline $\begin{array}{l}\text { Ya } \\
\text { Tidak }\end{array}$ & $\begin{array}{c}100 \\
4\end{array}$ & $\begin{array}{c}96,2 \\
38\end{array}$ \\
\hline Total & 104 & 100,0 \\
\hline
\end{tabular}

Berdasarkan tabel 2. didapatkan hasil dari 104 responden bahwa responden yang melakukan upaya menjaga berat badan sebanyak 100 responden $(96,2 \%)$ dan yang tidak melakukan upaya menjaga berat badan sebanyak 4 responden $(3,8 \%)$.

\section{Analisa Bivariat}

Tabel 3.

Crosstabulation Berdasarkan Hubungan Antara Tingkat Pengetahuan Body Mass Index (BMI) Dengan Upaya Menjaga Berat Badan Ideal Pada Remaja Di SMK Bina Insan Cendekia Tangerang Tahun $2020(\mathrm{n}=104)$

\begin{tabular}{|c|c|c|c|c|c|c|c|c|}
\hline \multirow{3}{*}{$\begin{array}{c}\text { Tingkat } \\
\text { Pengetahu } \\
\text { an }\end{array}$} & \multicolumn{4}{|c|}{$\begin{array}{c}\text { Upaya Menjaga Berat } \\
\text { Badan Ideal }\end{array}$} & \multicolumn{2}{|c|}{ Total } & \multirow{3}{*}{$\begin{array}{c}\text { OR } \\
95 \% \\
\mathrm{Cl}\end{array}$} & \multirow[t]{3}{*}{$\begin{array}{c}P \\
\text { value }\end{array}$} \\
\hline & \multicolumn{2}{|c|}{$\mathrm{Ya}$} & \multicolumn{2}{|c|}{ Tidak } & & & & \\
\hline & $\mathrm{N}$ & $\%$ & $\mathrm{~N}$ & $\%$ & $\mathrm{~N}$ & $\%$ & & \\
\hline Baik & 97 & $98,0 \%$ & 2 & $2,0 \%$ & 99 & $100,0 \%$ & & \\
\hline Kurang & 3 & $60,0 \%$ & 2 & $40,0 \%$ & 5 & $100,0 \%$ & 32,33 & 0,002 \\
\hline Total & 100 & $96,2 \%$ & 4 & $3,8 \%$ & 104 & $100,0 \%$ & & \\
\hline
\end{tabular}

Berdasarkan tabel 3. didapatkan hasil dari 104 responden yang berpengetahuan baik dan melakukan upaya menjaga berat badan ideal sebanyak 97 responden (98\%), sedangkan responden yang 
berpengetahuan baik dan tidak melakukan upaya menjaga berat badan ideal sebanyak 2 responden (2\%). Responden yang berpengetahuan kurang dan melakukan upaya menjaga berat badan ideal sebanyak 3 responden $(60 \%)$, sedangkan responden yang berpengetahuan kurang dan tidak melakukan upaya menjaga berat badan ideal sebanyak 2 responden (40\%).

Berdasarkan uji Chi Square bahwa $P$ value $0,002<0,05$ maka dapat dinyatakan $\mathrm{H}_{0}$ ditolak dan $\mathrm{H}_{a}$ diterima artinya ada hubungan antara tingkat pengetahuan Body Mass Index (BMI) dengan upaya menjaga berat badan ideal pada remaja di SMK Bina Insan Cendekia Tangerang tahun 2020. Dari hasil analisis diperoleh pula nilai $\mathrm{OR}=$ 32,33 artinya siswa/siswi yang berpengetahuan baik memiliki peluang 32,33 kali untuk melakukan upaya menjaga berat badan ideal dan siswa/siswi yang berpengetahuan kurang memiliki peluang 32,33 kali untuk tidak melakukan upaya menjaga berat badan ideal.

Tabel 4.

Hasil Analisis Koefisiensi Korelasi Tingkat Pengetahuan dengan Upaya Menjaga Berat Badan Ideal

\begin{tabular}{llrr}
\hline & & \multicolumn{1}{c}{$\begin{array}{c}\text { Tingkat } \\
\text { Pengetahuan }\end{array}$} & $\begin{array}{c}\text { Upaya } \\
\text { Menjaga Berat } \\
\text { Badan Ideal }\end{array}$ \\
\hline Tingkat & Pearson Correlation & 1 &, $537^{* *}$ \\
Pengetahuan & Sig. (2-tailed) & 104 &, 000 \\
& $\mathrm{~N}$ &, $537^{* *}$ & 104 \\
\hline Upaya Menjaga & Pearson Correlation &, 000 & 1 \\
Berat Badan Ideal & Sig. (2-tailed) & 104 & 104 \\
& $\mathrm{~N}$ & & \\
\hline
\end{tabular}

Berdasarkan tabel 4. korelasinya kuat dan bentuk menunjukkan nilai signifikansi hubungannya ialah positif. Semakin $0,000<0,05$ maka berkorelasi. tinggi Tingkat Pengetahuan maka Karena 0,537 termasuk kedalam 0,41 makin tinggi pula Upaya Menjaga s/d 0,70 jadi memiliki korelasi Berat Badan ideal. dengan derajat hubungan

Tabel 5.

Hasil Analisis Uji Wilcoxon Tingkat Pengetahuan dan Upaya Menjaga Berat Badan Ideal

Asymp. Sig. (2-tailed)

\section{Tingkat Pengetahuan - Upaya Menjaga Berat Bdan Ideal}

Berdasarkan tabel 5. didapatkan hasil pengolahan data uji wilcoxon pada variabel tingkat pengetahuan dengan upaya menjaga berat badan ideal hail asymp. Sig (2tailed) adalah 0,000 < 0,05. Maka , 000

dapat disimpulkan bahwa $\mathrm{H}_{\mathrm{o}}$ ditolak dan $\mathrm{H}_{\mathrm{a}}$ diterima, yang artinya terdapat hubungan bermakna antara variabel tingkat pengetahuan dengan upaya menjaga berat badan ideal. 


\section{PEMBAHASAN}

Berdasarkan tabel 3. didapatkan hasil dari 104 responden yang berpengetahuan baik dan melakukan upaya menjaga berat badan ideal sebanyak 97 responden (98\%), sedangkan responden yang berpengetahuan baik dan tidak melakukan upaya menjaga berat badan ideal sebanyak 2 responden (2\%). Responden yang berpengetahuan kurang dan melakukan upaya menjaga berat badan ideal sebanyak 3 responden $(60 \%)$, sedangkan responden yang berpengetahuan kurang dan tidak melakukan upaya menjaga berat badan ideal sebanyak 2 responden (40\%).

Berdasarkan uji Chi Square yang tertera pada tabel 3 . bahwa $P$ vale $0,002<0,05$ maka dapat dinyatakan $\mathrm{H}_{\mathrm{a}}$ diterima dan $\mathrm{H}_{\mathrm{o}}$ ditolak artinya ada hubungan antara tingkat pengetahuan Body Mass Index (BMI) dengan upaya menjaga berat badan ideal pada remaja di SMK Bina Insan Cendekia Tangerang tahun 2020. Dari hasil analisis diperoleh pula nilai $\mathrm{OR}=32,33$ artinya siswa/siswi yang berpengetahuan baik memiliki peluang 32,33 kali untuk melakukan upaya menjaga berat badan ideal dan siswa/siswi yang berpengetahuan kurang memiliki peluang 32,33 kali untuk tidak melakukan upaya menjaga berat badan ideal.

Dari hasil penelitian juga dapat diketahui bahwa tingkat pengetahuan seseorang akan mempengaruhi dirinya dalam melakukan upaya menjaga berat badan. Hal ini dapat ditunjukan dengan semakin tinggi tingkat pendidikan responden akan menyadari dan mengerti akan pentingnya melakukan upaya menjaga berat badan agar tetap ideal, tentu saja semakin tinggi tingkat pendidikan semakin matang dan rasional dalam mengambil keputusan dan dapat juga didukung oleh adanya pengalaman pribadi dan informasi yang didapat baik melalui media massa, keluarga terdekat ataupun sumber-sumber lainnya.

Hasil penelitian ini diperkuat oleh teori yang dikemukakan oleh Lestari (2015) bahwa, perilaku manusia merupakan hasil daripada segala macam pengalaman serta interaksi manusia dengan lingkungannya yang terwujud dalam bentuk pengetahuan, sikap dan tindakan. Karena presentase tertinggi terjadi pada responden yang memiliki kategori berpengetahuan baik dan melakukan upaya menjaga berat badan sebanyak 97 responden (98\%).

Hasil penelitian ini sejalan dengan penelitian yang dilakukan oleh Fuadi Raja Baja (2019) dengan judul hubungan tingkat pengetahuan diet dan aktivitas fisik terhadap status gizi pada siswa Sekolah Menengah Atas Negeri 1 Yogyakarta. Hasil uji Chi-square diperoleh $\mathrm{p}=$ $0,01 \quad(p<0,05)$, maka dapat disimpulkan ada hubungan yang bermakna antara tingkat pengetahuan dengan aktivita fisik terhadap status gizi.

Penelitian lain yang tidak sejalan dengan penelitian ini adalah penelitian yang dilakukan oleh Mirna Rahmasari (2016) dengan judul hubungan persepsi tubuh dengan diet dan aktivitas fisik pada mahasiswa baru IPB dengan status gizi lebih. Berdasarkan hasil uji korelasi Spearman bahwa bahwa tidak terdapat hubungan yang signifikan antara pengetahuan diet penurunan berat badan dengan penerapan diet penurunan berat badan ( $P=0.786 ; r=-0.088)$. Hal ini menunjukkan bahwa semakin baik pengetahuan diet penurunan berat badan pada subjek belum tentu subjek juga akan menerapkan diet penurunan berat badan. Hal ini 
dikarenakan subjek yang menerapkan diet penurunan berat badan adalah subjek yang mempunyai pengetahuan mengenai diet penurunan berat badan pada kategori kurang (48.7\%) dan sedang (51.3\%).

Berdasarkan hasil penelitian ini, didapatkan data sebagian besar responden memiliki pengetahuan baik. Pengetahuan baik yang dimiliki oleh responden dapat meningkatkan responden dalam memutuskan tindakan yang teap untuk dirinya. Hal ini yang mendorong responden untuk melakukan upaya menjaga berat badan saat mengetahui batasan normal Body Mass Index (BMI). Penelitian ini menjawab permasalahan penelitian bawha pengetahuan yang baik di dukung dengan adanya usia semakin matang, pendidikan yang tinggi, sumber informasi serta lingkungan sosial yang baik mampu mendukung tingkat pengetahuan pada responden.

\section{KESIMPULAN}

Berdasarkan hasil penelitian dan pembahasan tentang Hubungan Antara Tingkat Pengetahuan Body Mass Index (BMI) dengan Upaya Menjaga Berat Badan Ideal Pada Remaja di SMK Bina Insan Cendekia Tangerang (BICTA) Tahun 2020 pada 104 responden, maka peneliti mendapat kesimpulan sebagai berikut :

a. Tingkat pengetahuan tentang Body Mass Index (BMI) yang baik sebanyak 99 responden $(95,2 \%)$ dan yang berpengetahuan kurang sebanyak 5 responden $(4,8 \%)$.

b. Responden yang melakukan upaya menjaga berat badan ideal sebanyak 100 responden $(96,2 \%)$ dan yang tidak melakukan upaya menjaga berat badan sebanyak 4 responden $(3,8 \%)$. c. Ada hubungan antara tingkat pengetahuan Body Mass Index (BMI) dengan upaya menjaga berat badan ideal pada remaja.

\section{SARAN}

Dalam penelitian ini peneliti masih memiliki banyak kekurangan dan jauh dari kata sempurna karena keterbatasan yang ada atau faktor lainnya, karena hal tersebut peneliti menyarankan sebagai berikut :

a. Bagi Responden

Hasil penelitian ini diharapkan bisa memiliki manfaat sebagai wawasan untuk responden yang membutuhkan informasi mengenai hubungan antara tingkat pengetahuan Body Mass Index (BMI) dengan upaya menjaga berat badan ideal pada remaja.

b. Bagi Institusi Pendidikan

Hasil penelitian ini diharapkan dapat dimanfaatkan bagi institusi pendidikan untuk menambah pustaka atau referensi mahasiswa untuk bahan belajar diperpustakaan dan dapat dikembangkan lagi.

c. Bagi Peneliti Selanjutnya

Bagi peneliti selanjutnya diharapkan untuk melakukan penelitian selanjutnya dengan menambahkan variabelvariabel lainnya yang berkaitan dengan Body Mass Index (BMI), seperti penerapan diet penurunan berat badan maupun pengaruh Body Mass Index (BMI) terhadap kejadian obesitas pada remaja. 
DAFTAR PUSTAKA

A. S. Hamidin. (2010). Kebaikan Air Putih: Terapi Air untuk Penyembuhan, Diet, Kehamilan dan Kecantikan. Yogyakarta: Media Pressindo.

Abramowitz, M. (2014). Diseases and Disorder: Obesity. USA: Lucent Books.

Agoes, Dariyo. (2013). Psikologi Perkembangan Dewasa Muda. Jakarta: PT Gramedia Widiasarana.

Almada, Syukra dan Sriani, Yustina. (2015). Buku Ajar Ilmu Kesehatan Masyarakat (IKM). Jakarta: Deepublish.

Altmatsier S, Susirah S, Moesijanti S. (2011). Gizi seimbang dalam daur kehidupan. Jakarta: Gramedia Pustaka Utama.

Anto J. Hadi. (2019). Literatur Review Model Modifikasi Intervensi Pencegahan Obesitas. Sidoarjo: Indomedia Pustaka.

Arikunto, S. (2014). Prosedur Penelitian Suatu Pendekatan Praktik. Jakarta: Rineka Cipta.

Arisman. (2011). Diabetes Mellitus : Dalam Buku Ajar Ilmu Gizi Obesitas dan Diabetes Mellitus dan Dislipidemia. Jakarta: EGC.

Baja, F. R. (2019). Hubungan Tingkat Pengetahuan Diet Dan Aktivitas Fisik Terhadap Status Gizi Pada Siswa Sekolah Menengah Atas Negeri 1 Yogyakarta. Fakultas Ilmu Keolahragaan. Universitas Negeri Yogyakarta.

Bungin, M. B. (2017). Metodologi Penelitian Kuantitatif: Komunikasi, Ekonomi, dan Kebijakan Publik Serta Ilmu-Ilmu Lainnya Edisi Kedua. Jakarta: Kencana.

Dhara, S., \& Chatterjee, K. (2015). A Study of Vo2max in Relation with Body Mask Index (BMI) of Physical Educaion Students. Research Journal of Physical Education Science, Vol. 3 No. 6 9-12.

Djamaluddin, Darwis. (2015). Mendidik Remaja Nakal. Yogyakarta: Semesta Hikmah.

Djiwandono, P.I. (2015). Meneliti itu Tidak Sulit: Metodologi Penelitian Sosial dan Pendidikan Bahasa. Yogyakarta: Deepublish Publisher. (Google eBook): https: / /books.google.co.id/ books?id=iWqEDwAAQBAJ\&pr intse $=$ frontcover\&dq=Djiwa ndono, $+2015 \& h l=$ id\&sa $=X \& v e$ $\mathrm{d}=2$ ahUKEwjckoaR1ZLqAhX37 XMBHQK3ACMQ6AEWAXoECA QQAg\# $\mathrm{v}=$ onepage\& $\mathrm{q}=$ Djiwand ono\%2C $\% 202015 \& f=$ false

Donsu, T.D.J. (2017). Psikologi Keperawatan, Aspek-Aspek Psikologi, Konsep Dasar Psikologi, Teori Prilaku Manusia. Yogyakarta: Pustaka Baru Press.

Ghozali, Imam. (2018). Aplikasi Analisis Multivariate dengan Program IBM SPSS 25. Semarang: Badan Penerbit Universitas Diponegoro.

Hendra, Chirtine., dkk. (2016). Faktor - Faktor Risiko Terhadap Obesitas Pada Remaja Di Kota Bitung. Jurnal e-Biomedik (eBm), Volume 4, Nomor 1, JanuariJuni 2016.

Hidayati, R.D. (2017). Hubungan Asupan Lemak Dengan Kadar Trigliserida Dan Indeks Massa Tubuh Sivitas Akademika UNY. Jurnal Prodi Biologi, (6)1, 25-33.

Hidayat, A.A. (2014). Metode Penelitian Keperawatan dan Teknik Analisis Data. Jakarta: Salemba Medika 
Indah, dkk. (2014). Status Gizi Berdasarkan Pola Makan Anak Sekolah Di Kecamatan Rajeg Tangerang. Indonesian Journal Of Human Nutrition. Desember 2014, Vol. 1 No.2 : 135 - 148.

Irianto, P. (2017). Pedoman Gizi Lengkap Keluarga dan Olahragawan. Yogyakarta: CV. Andi Offset.

Jayanata, Christopher Emille. (2013). Gaya Hidup Organik: Sehat Tanpa Mahal. Bandung: Qanita.

KEMENKES RI. (2020). Profil Kesehatan Indonesia. Jakarta : Kementrian Kesehatan Republik Indonesia. https: / /www.kemkes.go.id/ article/view/20012600004/gi zi-saat-remaja-tentukankualitas-keturunan.html Diakses pada tanggal 24 Januari 2020 pukul 15:00 WIB.

Kumalasari, I. dan Andhyantoro, I. (2012). Kesehatan Reproduksi. Jakarta: Salemba Medika.

Kurdanti, Weni, Isti Suryani, Nurul Huda Syamsiatun, Listiana Purnaning Siwi, Mahardika Marta Adityanti, Diana Mustikaningsih, and Kurnia Isnaini Sholihah. "Faktor-faktor yang mempengaruhi kejadian obesitas pada remaja." Jurnal Gizi Klinik Indonesia 11, no. 4 (April 30, 2015): 179. https://doi.org/10.22146/ijc n.22900.

Kusumawardani, Winda, and Farapti Farapti. "Hubungan Perilaku Diet Dengan Massa Lemak Tubuh Pada Remaja Putri Di SMA Negeri 5 Surabaya." Amerta Nutrition 4, no. 1 (March 15, 2020):

65. https://doi.org/10.20473/a mnt.v4i1.20 20.65-71.

Lestari, T. (2015). Kumpulan teori untuk kajian pustaka penelitian kesehatan. Yogyakarta: Nuha medika.

Masturoh, Imas dan T, Nauri Anggita. (2018). Bahan Ajar Rekam Medis Dan Informasi Kesehatan (RMIK): Metodologi Penelitian Kesehatan. Jakarta: Kementerian Republik Indonesia.

Nasrudin, Juhana. (2019). Metodologi Penelitian Pendidikan: Buku Ajar Praktis Cara Membuat Penelitian. Bandung: Panca Terra Firma.

Notoatmodjo, S. (2014). Ilmu Perilaku Kesehatan. Jakarta: Rineka Cipta.

Nursalam. (2016). Metodologi Penelitian Ilmu Keperawatan: Pendekatan Praktis ed 4. Jakarta: Salemba Medika.

Profil Kesehatan Provinsi Banten Tahun 2019. https: / / dinkes.bantenprov.g o.id/read/profil-kesehatanprovinsi-bant/180/ProfilKesehatan-Provinsi-BantenTahun-2019.html Diakses pada tanggal 05 Maret 2020 pukul 08:15 WIB.

Rachmawati, Muchnuria. (2012). Mencegah Obesitas (Problema Obesitas Pada Remaja). Malang: Universitas Brawijaya Press (UB Press).

Ramadhani, A. D. (2013). Hubungan Kontrol Tekanan Darah Dengan Indeks Massa Tubuh Pada Pasien Hipertensi. Fakultas Kedokteran dan IImu Kesehatan. Universitas Islam Negeri Syarif Hidayatullah Jakarta.

Santoso, I. (2013). Manajemen Data Untuk Analisis Data Penelitian Kesehatan. 
Yogyakarta: Gosyen

Publishing.

Sugiyono. (2017). Metode Penelitian Kuantitatif, Kualitatif dan $R \& D$. Bandung: PT Alfabet.

Sugiyono. (2017). Statistika Untuk Penelitian. Bandung: Alfabeta, CV.

Sugiyono. (2019). Metode Penelitian Kuantitatif, Kualitatif dan R\&D. Bandung: PT Alfabet.

Suryani dan Hendryadi. (2015). Metode Riset Kuantitatif : Teori Dan Aplikasi Pada Penelitian Bidang Manajemen Dan ekonomi Islam. Jakarta: Prenadamedia Group.

Susila \& Suryanto. (2015). Metodologi Penelitian Retrospective/ Ex Post Facto Case Control Causal Correlation. Klaten: BOSSSCRIPT.

Wawan, A dan Dewi, M. (2011). Teori dan Pengukuran Pengetahuan, Sikap dan Perilaku Manusia. Cetakan II. Yogyakarta: Nuha Medika. 